\title{
Security Constrained Augmentation for Transmission System Considering Preferences of Market Players on Expansion Options
}

\author{
M. R. Hesamzadeh, Student Member, IEEE, N. Hosseinzadeh, Member, IEEE and \\ P. J. Wolfs, Senior Member, IEEE
}

\begin{abstract}
This paper presents a new approach for transmission expansion planning in unbundled electricity industry. The approach considers the power market and technical criteria for selecting the most effective expansion options. Perfect competition, a stable electricity market, and a lower price of electricity at different market players' locations have been addressed in the proposed methodology. Reliability criteria have been considered in terms of transmission system security and sustainable load serving.

To consider the preferences of market players for different expansion options, firstly, importance degree of market players are determined based on a digitised band. Then a fuzzy linguistic variable is assigned to the preference of each market player to the transmission options. Finally, the quantified linguistic variables are used to weight planning criteria and select the final plan. The results of applying the proposed methodology to the introduced case study are very promising.
\end{abstract}

\section{INTRODUCTION}

$\mathrm{R}$ estructuring of electricity industries have changed many concepts of the operation and planning of the power systems and caused many new issues.

As an example, high voltage transmission systems designed for a traditional electricity market are used by many market players as an electrical transmission path. In this new environment, transmission system has to be able to tackle many technical and market-based problems that stem from competition among market players. It goes with out saying that transmission system planning is a key factor in not only providing a reliable power system, but also improving the efficiency of the electricity market as well as satisfying the preferences of various market players.

Given the different structures of electricity markets implemented worldwide [1] and the link between expansion planning of transmission system and the structure of electricity market, there is various procedures to plan the expansion of transmission systems and these range from accommodating voltage stability issues in Eastern Australian Transmission System, [2], [3], to market based transmission system planning in Pennsylvania, New Jersey, and Maryland (PJM) [4].

Among various algorithms to plan transmission systems that are used in different parts of the world [5], [6], it is possible to distinguish some common issues [6] including, when and where transmission assets should be installed [7], their funding and cost recovery [8].

Indeed, relationship and coordination of transmission and generation planning [9], accommodating uncertain factors and risks [8], [9], [10], increasing flexibility and robustness, reliability criteria [11], and satisfaction of market players [12] are main topics which many researchers are currently working on.

The synthesis planning models can be classified into two types: heuristic [16] and mathematical optimization. However, there are tools that have characteristics of both type of models and they are termed meta-heuristic. Hybrid methods [13], [14], [15] are combination of the aforementioned methods for gathering the accuracy of meta heuristic and mathematical algorithms and speed of heuristic methods [6].

This paper proposes a forward heuristic approach that can be used to select the quasi-optimal expansion pattern in a set of transmission planning options considering preference degree of market players with transmission system reliability constraints.

The proposed methodology is based on effectively defined sensitivity criteria for considering,

- improvement of market efficiency (by measuring congestion revenue of the system);

- increasing transmission reliability for sustainable load serving (by measuring value of lost load);

- increasing transmission security (by contingency analysis);

- decreasing electricity price (by using average of locational marginal price )

- the preference degree of market players (by fuzzy concept) and

- efficient transmission line siting (by line effectiveness measurement).

This paper is organized in three sections. An introduction to the problem is collected in section1. To present the proposed methodology concisely, section 2 is divided in two subsections. In the first subsection, namely PHASE 1, the reference electricity market is detailed and mathematically modelled. Similarly, in PHASE 2, the proposed transmission planning methodology is explained. Proposed methodology detailed in section 2 has been applied on a test case in numerical studies section. Section 4 sums up this paper.

\section{PROPOSED APPROACH FOR TRANSMISSION PLANNING}

The proposed methodology is detailed through two phases, namely phase 1 and phase 2 . In phase 1 , the reference electricity market is mathematically modelled to be used for assessment of transmission planning options from the angle of market criteria. Phase 2 is dominantly involved in evaluating the prevailing options for expansion from the view 
point of both market criteria and technical criteria accommodating the preference degree of market players in to final decision making. These phases are detailed in two following subsections.

\section{A. PHASE 1: Mathematical Modelling of Reference Electricity Market (REM)}

One-sided pool in which only suppliers can bid, and costbased pool in which suppliers are not free to offer any price, is used as electricity market structure in this paper, Australian electricity market structure is in this category.

In this electricity market environment, all generating companies offer price-quantity pairs for the supply of electricity which forms an aggregated supply curve. The offered prices by suppliers are based on predetermined variable costs. On the demand side, the market operator may forecast demand and dispatch generating units against this. Figure 1 presents the energy flow (MWh) and cash flow $(\$ / \mathrm{MWh})$ of the reference electricity market with corresponding organizations in Australian electricity market and figure 2 shows price-quantity curve of electricity market which is used for mathematical formulation of the reference electricity market.

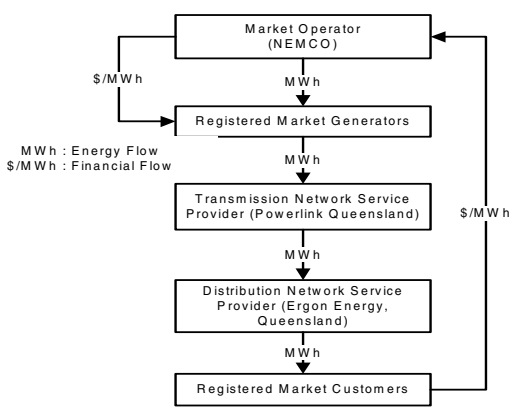

Fig. 1 Energy and financial flows for reference electricity market structure

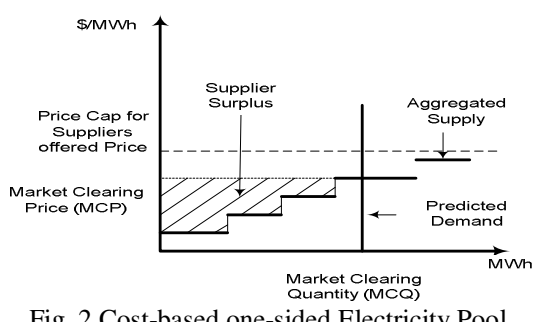

Fig. 2 Cost-based one-sided Electricity Pool

The mathematical modelling of REM is based on a Locational Marginal Price (LMP) calculation.

We assume marginal cost of generator $\mathrm{g}$ as a linear function: $\mathrm{MCg}=\mathrm{c}_{\mathrm{g}}$

Where in equation (1), $\mathrm{MC}_{\mathrm{g}}$ is the marginal cost function for generator $\mathrm{g}$ and $\mathrm{cg}$ is the marginal cost constant of corresponding generator. Each registered generator in the market offers its bidding curve to the Independent System Operator (ISO) based on its understanding of the market and its technology level for producing power.

After receiving all information about generator marginal costs, ISO forecasts the demand and dispatches generators over the predicted load. In this step, Economic Dispatch Module (EDM) is activated which is based on a Merit-Order dispatch
DC load flow (DCLF) is used in the next step for checking the generation pattern obtained by EDM, called optimum power market operating point, from viewpoint of power system thermal limits. If transmission system supports optimum power market operating point, the market will be cleared at Market Clearing Price (MCP), which is marginal price of last dispatch generator.

But in most cases, optimum power market operating point is not a secure power system operating point in terms of transmission line thermal limits. For removing congestion from overloaded transmission lines, a DC based Security Constrained Optimal Power Flow (SCOPF) formulated in (3) is activated and solved by linear programming (LPOPF).

$$
\begin{aligned}
& \text { Min } \sum_{i=1}^{N g} c_{i} p_{i} \\
& \text { Such that }: \\
& f_{l}^{0}+\sum_{i=1}^{N_{g}} \frac{\partial f_{l}}{\partial p_{i}} \Delta p_{i} \leq f_{l}^{M a x}, l=1, \ldots, N_{\text {cong }} \\
& f_{l}^{0}+\sum_{i=1}^{N g}\left(\frac{\partial f_{l}}{\partial p_{i}}+\frac{\partial f_{i}}{\partial f_{k}} \times \frac{\partial f_{k}}{\partial p_{i}}\right) \Delta p_{i} \leq f_{l}^{M a x}, l=1, \ldots, N_{\text {mont }}, k=1, \ldots, N_{\text {cont }} \\
& p_{i}^{\text {Min }} \leq p_{i} \leq p_{i}^{\text {Max }}, i=1, \ldots, N_{g} \\
& \sum_{i=1}^{N g} p_{i}=P_{\text {load }}+P_{\text {spimining resere }}+P_{\text {loss }}, i=1, \ldots, N_{g}
\end{aligned}
$$

where,

$\mathrm{N}_{\mathrm{g}}$ : number of committed generators

$c_{i}$ : marginal production cost of generator i in $\$ / M W h$

$\mathrm{p}_{\mathrm{i}}$ : production level of generator $\mathrm{i}$ in MW

$\mathrm{f}_{1}^{0}$ : normal flow of line 1 in MW

$\frac{\partial f_{l}}{\partial p_{l}}$ : Sensitivity of change of power passing through line 1 $\partial p_{i}$

with respect to change in injected power to bus $i$

$\mathrm{f}_{1}^{\text {max }}$ : maximum flow of line 1 in MW

$\mathrm{N}_{\text {cong }}$ : total number of congested transmission lines

$\frac{\partial f_{l}}{\partial f_{k}}$ : sensitivity of change of power passing through line 1 $\frac{\partial f_{k}}{\partial f_{k}}$

with respect to outage of line $\mathrm{k}$

$\mathrm{N}_{\text {mont }}$ : total number of monitored transmission lines

$\mathrm{N}_{\text {cont }}$ : total number of contingencies

$\mathrm{p}_{\mathrm{i}}^{\text {Min. }}$ : min production level of generator $\mathrm{i}$ in MW

$\mathrm{p}_{\mathrm{i}}^{\text {Max }}$ : max production level of generator $\mathrm{i}$ in MW

$\mathrm{P}_{\text {load }}$ :total connected load to the transmission system

$\mathrm{P}_{\text {spinning reserve }}$ :total spinning reserve of the transmission system $\mathrm{P}_{\text {loss }}$ :total transmission loss

In (2), inequality set 2-1 refers to production cost of committed generators. In 2-2, congested transmission lines are formulated through sensitivity of line flow to the injected power at the generator connection points.

Security of transmission system is guarantied by inequality set 2-3, taking in to account the predefined outages and monitored transmission lines.

Inequality set 2-4 models the technological limitations of the generation plants for producing power and finally load balance equation is formulated in 2-5. In this equation spinning reserve of generator set and loss of transmission system are taken into consider by addition of constant terms to the total connected load to the under study transmission system.

After having a secure power system, LMP algorithm is used for finding the price signals at each transmission connection point. Marginal transmission lines (MTL) are defined as 
those ones with power flow right at their maximum limit. If no marginal transmission line exits for the new generation pattern, the power market will clear at market clearing price which is the marginal price of the last generator dispatched. In the case of MTL, two sets of equations are needed for finding the LMP at each bus which is formulated in equation (3).

$$
\begin{aligned}
& \sum_{l=1}^{N_{M T L}} \sum_{i=1}^{N g} \frac{\partial f_{l}}{\partial p_{i}} \Delta p_{i}=\sum_{l=1}^{N_{\text {MTL }}} \frac{\partial f_{l}}{\partial p_{i}} \\
& \sum_{i=1}^{N_{g}} \Delta p_{i}=1
\end{aligned}
$$

By solving the two sets of equations presented in (3), the contribution of each generator for serving $1 \mathrm{MW}$ load at each transmission connection point is calculated.

LMP can be found by multiplying generator contribution by their unit marginal cost [16-17-18].

The methodology detailed above is used as Electricity Market Operation Simulator in section PHASE 2 for the measuring of electricity market indices.

\section{B. PHASE 2: Suggested Transmission Planning Steps}

The heuristic approach has been widely used for transmission expansion planning in vertically integrated electricity market. It is based on intuitive analysis and relatively close to the way that engineers think. It can give a good design scheme based on the experience and analysis.

The goal is to choose a subset of lines from the set of options to expand the network, and to connect new generators and new loads while maximizing market efficiency, and minimizing the value of lost loads by installing the most effective transmission lines with the lowest investment cost.

The proposed forward heuristic approach follows the following steps:

Step1: collect power system data including the generators, transmission line, and load data and also power market data including the bidding strategy of each generator and forecasted load by the power market operator

Step2: generate all options for expansion of transmission system

Step3: Run electricity market operation simulator detailed in section 1

Step4: Find System Performance indices:

This paper proposes two indices for measuring the degree of competition in the designed transmission system along with power system reliability.

a) Power Market Index - System Congestion Revenue (CRsys) which is defined as the difference between total money that customers pay to the electricity market for using electricity and total money that generators take from power market for producing power.

$$
C R_{s y s}=\sum_{g=1}^{N C G R} \lambda_{g} \times p_{g}-\sum_{l=1}^{N L D} \lambda_{l} \times p_{l}
$$

In equation (4), $\lambda_{g}$ is the LMP at the connection point of generator $\mathrm{g}$ in $\$ / \mathrm{MWh}$ and $\mathrm{pg}$ is the generation level of same generator in MW. Similarly, $\lambda_{l}$ is the LMP at the connection point of load 1 in $\$ / M W h$ and $\mathrm{pl}$ is the load level of the same load in MW while NLD is the total number of loads in the system under study.

In a stable perfect competitive electricity market, the price of electricity at all transmission connection points are the same and obviously system congestion revenue is zero.

b) Power System Reliability Index - System Value of Lost Load $\left(\mathrm{VoLL}_{\text {sys }}\right)$ which is defined as the total load shedding in MW multiplied by the value of lost load in \$/MWh.

$$
V o L L_{s y s}=\sum_{l=1}^{N L D} \operatorname{VoLL} \times\left(p_{l}^{\operatorname{Max}}-p_{l}\right)
$$

$\mathrm{p}_{1}^{\mathrm{Max}}$ is the value of the load that has to be served by the designed transmission system and $\mathrm{pl}$ is the level of the load that can be supplied by the existing capacity of transmission system. VoLL value of 1000 \$/MWh is used in our case study, which does not resemble those used in actual electricity market like $10000 \$ / \mathrm{MWh}$ for the Australian National Electricity Market [18].

c) Transmission Expansion Cost: cost of expansion is calculated by considering construction cost of adding new corridors for transferring power from one transmission connection point to another $\left(\right.$ cost $\left._{i}\right)$.

Step5: find option performance indices:

Suggested performance indices for evaluating the set of

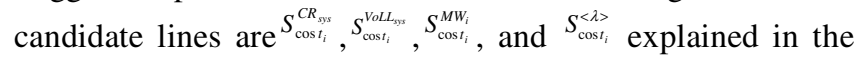
following subsections.

a) Sensitivity of the system congestion revenue $\left(\mathrm{CR}_{\mathrm{sys}}\right)$ with respect to construction cost of option i, $S^{C R_{s y s}} t_{i}$, can be found by:

$$
S_{\cos _{i}}^{C R_{s s}}=-\frac{\left(C R_{s y s}^{(w)}-C R_{s y s}^{(w-1)}\right)}{\cos t_{i}}=-\frac{\delta C R_{s y s}}{\cos t_{i}}
$$

In which $C R_{s y s}^{(w)}$ and $C R_{s y s}^{(w-1)}$ refer to system congestion revenue after and before addition of line i respectively.

b) Sensitivity of the system value of lost load (VoLLsys) with respect to construction cost of option $\mathrm{i}$, $S_{\text {cost } t_{i}}^{V o L L_{s s}}$, can be found by:

$$
S_{\cos _{i}}^{V o L L_{p s}}=-\frac{\left(V o L L_{s y s}^{(w)}-V o L L_{s y s}^{(w-1)}\right)}{\cos t_{i}}=-\frac{\delta V o L L_{s y s}}{\cos t_{i}}
$$

In equation (8) $V o L L_{s y s}^{(w)}$ and $V^{V L L L_{s y s}^{(w-1)}}$ refer to system congestion revenue after and before addition of line i respectively.

c) $\quad S_{\cos t_{i}}^{M W_{i}}$ is defined as the effectiveness index of the $\mathrm{i}^{\text {th }}$ option in terms of using the capacity of transmission line as high as possible. This index has the highest value for transmission line candidate which transmits more power at low investment cost so,

$$
S_{\cos t_{i}}^{M W_{i}}=\frac{M W_{i}}{\cos t_{i}}
$$

$\mathrm{MW}_{\mathrm{i}}$ is the power flow through transmission line candidate number $\mathrm{i}$, and cost $\mathrm{t}_{\mathrm{i}}$ is the construction cost of that option. 
d) $\quad S_{\cos t_{i}}^{<\lambda>}$ assesses the effect of addition of the $i^{\text {th }}$ transmission candidate with its associated cost $\left(\cos t_{i}\right)$ on the marginal price of electricity at each transmission connection point.

$$
S_{\cos _{i}}^{<\lambda>}=-\frac{\left(<\lambda>^{(w)}-<\lambda>^{(w-1)}\right)}{\cos t_{i}}=-\frac{\delta<\lambda>(9)}{\cos t_{i}}
$$

In equation (9), $\quad<\lambda>=\frac{\sum_{i=1}^{N B}\left|\lambda_{i}\right|}{N B}$ and is the mean of absolute values of the LMP of each transmission connection point while NB refers to total number of buses in the system.

Similarly, $\langle\lambda\rangle^{(w)}$ and $\langle\lambda\rangle^{(w-1)}$ refer to system congestion revenue after and before addition of line i respectively.

Step6: Find option appropriateness matrix $\left({ }^{A_{p \times q}}\right)$

Definition: $A_{p \times q}$ is a matrix with $\mathrm{p}$ as total number of expansion options, plans, and $\mathrm{q}$ as the total number of criteria. $\left[a_{i j}\right]$ as the ij element of A matrix is:

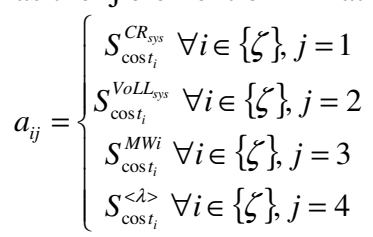

Where $\mathrm{i}$ is the option index, $\mathrm{j}$ is the criterion index, and $\{\zeta\}_{\text {is }}$ the set of all available options for expansion of transmission system.

Larger values of all these criteria indicate better conditions. Since the appropriateness index of each plan must be comparable versus different planning criteria, each column of matrix $\mathrm{A}$ is normalized based on the maximum absolute value of that column and then the whole matrix will be normalized again based on the absolute value of the new matrix.

$$
\begin{aligned}
& N_{i j}=\frac{a_{i j}}{\underset{\forall j}{\max \left(\left|a_{i j}\right|\right)}} \\
& N N_{i j}=\frac{n_{i j}}{{\max \left(\left|n_{i j}\right|\right)}_{\forall(i, j)}}
\end{aligned}
$$

In equation (11), $\mathrm{N}$ is matrix $\mathrm{A}$ for which each column is normalized based on the maximum absolute value of that column $\left(a_{i j}\right.$ for a specific $\mathrm{j}$ ) and the matrix $\mathrm{NN}$ defined by equation (12) is normalized version of matrix $\mathrm{N}$ based on the maximum absolute value of the elements $n_{i j}$ of matrix $N$.

Step7: Find the weighting factors of stakeholders in transmission planning in form of weighting/stakeholder matrix $\left([W S]_{1 \times s}\right)$

This matrix is subjective and regulatory authorities will have a strong view on the importance attributed to the different stakeholders. $\mathrm{q}$ in the [WS] matrix is the number of stakeholders in the market and

$$
\begin{array}{ll}
\text { - } & \sum_{i=1}^{s} w s_{i}=1 \\
\text { - } & 0 \leq w s_{i} \leq 1 \quad \forall \quad 1 \leq i \leq s
\end{array}
$$

Step8: Find the option/stakeholder preference matrix $\left({ }_{[P S]_{p \times s}}\right)$ To represent preference degree of each market player on each planning option, the following linguistic variables are used:

$$
\mathrm{Z}=\{\mathrm{VL}, \mathrm{L}, \mathrm{M}, \mathrm{H}, \mathrm{VH}\}
$$

Where VL, L, M, H, VH are abbreviations of very low, low, medium, high, and very high, respectively. It is difficult to find measures for introduced linguistics variables. This paper uses a scale (between 0 and 1) for measuring the linguistic variable set $Z$.

A project which has lowest interest might be valued 0 . Similarly, low interest, medium interest, high interest, and finally very high interest are valued $0.25,0.5,0.75$, and 1 respectively.

Step9: Find the weighted plan performance matrix $\left([P]_{p \times 1}\right)$

$$
\left[p_{i}\right]=(1 / s) \sum_{j=1}^{s} w s_{j} \times p s_{i j} \quad \forall 1 \leq i \leq p
$$

Step 10: Calculate plan performance vector $\left({ }_{[R]_{p \times 1}}\right)$

Plan performance vector which evaluate each plan based on the power market and power system indices is found as:

$$
\left[r_{i}\right]=\sum_{j=1}^{q} a_{i \times j} \quad \forall 1 \leq i \leq p
$$

Step 11: Find the most effective plan and add it to the base transmission system as in equation (17).

$$
i_{\text {optm }}=\left\{i \mid i=\max _{\forall 1 \leq i \leq p}\left(p_{i} \times r_{i}\right)\right\}
$$

Step 12: Take out optimum transmission plan from set of candidates $\{\zeta\}$ and add it to the network-line set $\{\psi\}$ as in equations (18) and (19).

$$
\begin{aligned}
& \{\zeta\}=\{\zeta\} \backslash\left\{i_{\text {optm }}\right\} \\
& \{\psi\}=\{\psi\} \cup\left\{i_{\text {optm }}\right\}
\end{aligned}
$$

Step 13: If system performance indices are within the standard limit, or if cost of expansion is higher than maximum investment cost, go to step 11 else go back to step 3.

Step 14: Print network-line set $\{\psi\}$ as the final transmission plan

The algorithm shown in figure 3 summarizes the proposed forward heuristic procedure.

\section{NUMERICAL STUDIES}

The proposed transmission expansion strategy is illustrated on a six-bus transmission system as shown in figure 4 . In this figure, the results of DCLF are shown as well, in which congested transmission lines are shown with bold lines. As it is clear from the figure, the optimum power market operating point in the horizon year can not be supported by the prevailing capacity of the transmission system.

Characteristics of generators, transmission lines, and load for the peak load of horizon year are given in Tables 1, 2, and 3. Table 4 summarizes transmission system plans for expansion of under study transmission system. Considered contingencies are collected in Table 5 while Table 6 and 
Table 7 are importance degree of market players and preference level of the each stakeholder in market options, respectively.

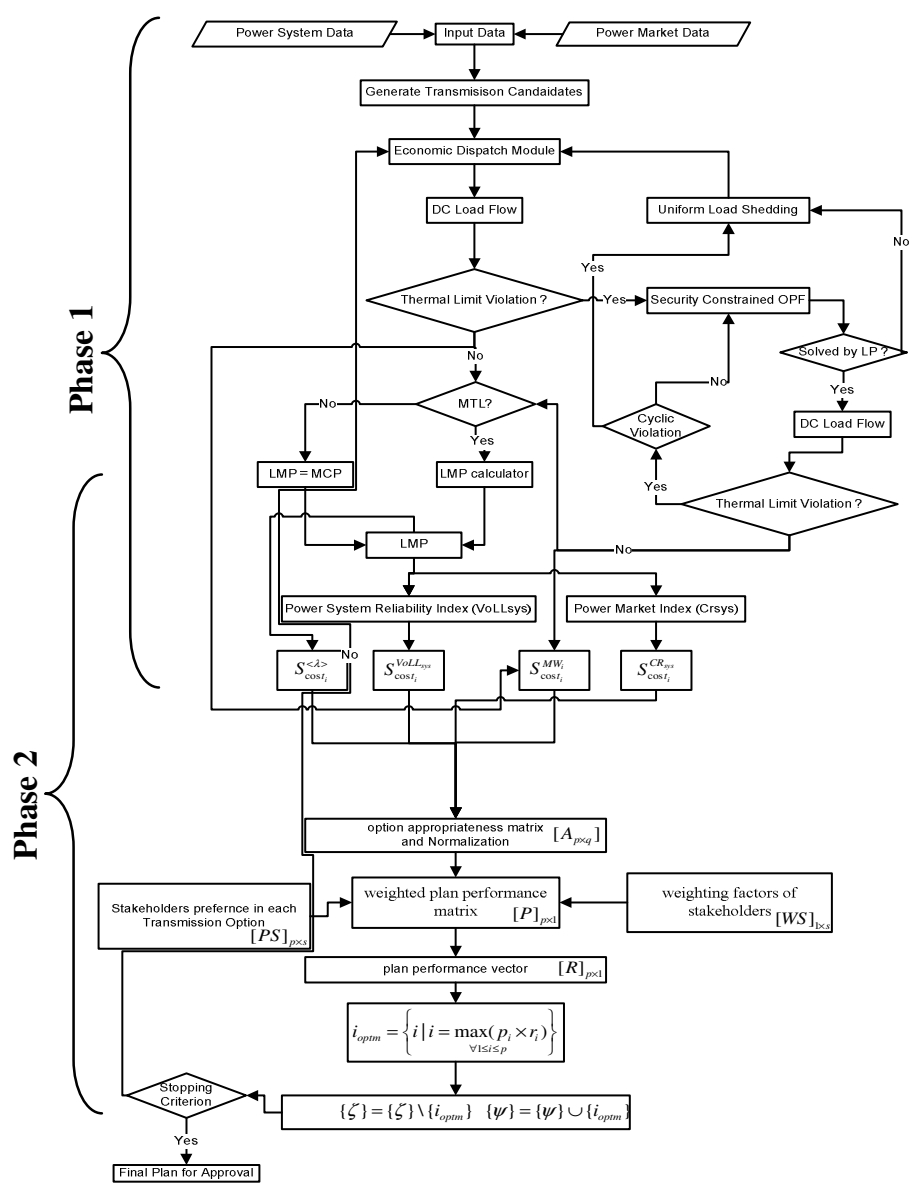

Fig. 3 Two Phase Proposed Transmission Planning Methodology Accommodating Security Constraints and Market Players Preference

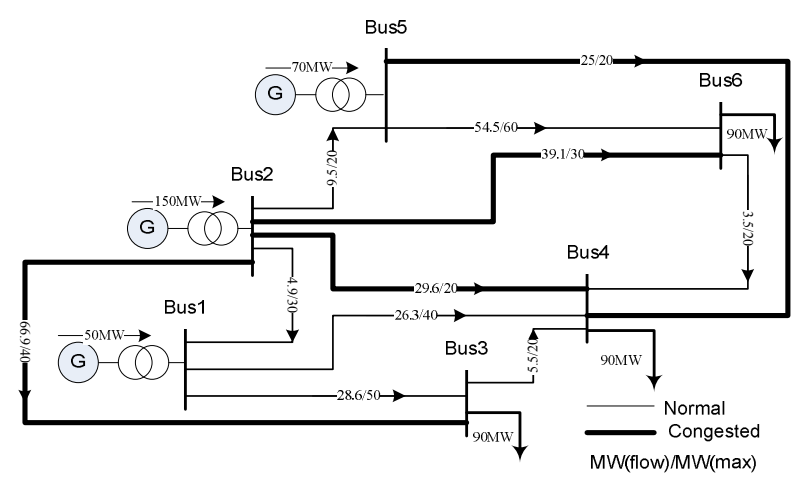

Fig. 4 Single-line diagram of a Six-bus transmission system

TABLE I

DATA OF GENERATORS

\begin{tabular}{|c|c|c|c|c|}
\hline Bus No. & Type & Min (p.u.) & Max(p.u.) & $\begin{array}{c}\text { Marginal cost* } \\
(100 \$ / M W h)\end{array}$ \\
\hline 1 & Gen. & 0.50 & 2.00 & 0.4147 \\
\hline 2 & IPP & 0.375 & 1.50 & 0.2577 \\
\hline 5 & IPP & 0.45 & 1.80 & 0.3930 \\
\hline
\end{tabular}

TABLE II

DATA OF THE TRANSMISSION SYSTEM

\begin{tabular}{|c|c|c|c|c|}
\hline From & To & R(p.u.) & X(p.u.) & $\begin{array}{c}\text { Max Thermal } \\
\text { Capacity(p.u.) }\end{array}$ \\
\hline 1 & 2 & 0.10 & 0.20 & 0.30 \\
\hline 1 & 3 & 0.05 & 0.20 & 0.50 \\
\hline 1 & 4 & 0.08 & 0.30 & 0.40 \\
\hline 2 & 5 & 0.05 & 0.25 & 0.20 \\
\hline 2 & 3 & 0.05 & 0.10 & 0.40 \\
\hline 2 & 4 & 0.10 & 0.30 & 0.20 \\
\hline 2 & 6 & 0.07 & 0.20 & 0.30 \\
\hline 5 & 4 & 0.12 & 0.26 & 0.20 \\
\hline 5 & 6 & 0.02 & 0.10 & 0.60 \\
\hline 3 & 4 & 0.20 & 0.40 & 0.20 \\
\hline 4 & 6 & 0.10 & 0.30 & 0.20 \\
\hline
\end{tabular}

TABLE III DATA OF LOADS

\begin{tabular}{|c|c|c|c|}
\hline Bus No. & Min (p.u.) & Load (p.u) & Max(p.u) \\
\hline 3 & 0 & 0.90 & 0.90 \\
\hline 4 & 0 & 0.90 & 0.90 \\
\hline 6 & 0 & 0.90 & 0.90 \\
\hline
\end{tabular}

TABLE IV

DATA OF THE TRANSMISSION EXPANSION OPTIONS

\begin{tabular}{|c|c|c|c|c|c|}
\hline No. & From & To & X(p.u.) & $\begin{array}{c}\text { Max Thermal } \\
\text { Capacity(p.u.) }\end{array}$ & $\begin{array}{c}\text { Cost } \\
\text { (p.u.) }\end{array}$ \\
\hline 1 & 1 & 2 & 0.10 & 0.40 & 200.00 \\
\hline 2 & 1 & 3 & 0.14 & 0.35 & 150.00 \\
\hline 3 & 1 & 4 & 0.12 & 0.38 & 160.00 \\
\hline 4 & 1 & 5 & 0.15 & 0.30 & 140.00 \\
\hline 5 & 1 & 6 & 0.18 & 0.58 & 130.00 \\
\hline 6 & 2 & 3 & 0.14 & 0.35 & 150.00 \\
\hline 7 & 2 & 4 & 0.12 & 0.38 & 180.00 \\
\hline 8 & 2 & 5 & 0.10 & 0.45 & 250.00 \\
\hline 9 & 2 & 6 & 0.12 & 0.38 & 180.00 \\
\hline 10 & 3 & 4 & 0.18 & 0.28 & 130.00 \\
\hline 11 & 3 & 5 & 0.18 & 0.28 & 135.00 \\
\hline 12 & 3 & 6 & 0.10 & 0.45 & 250.00 \\
\hline 13 & 4 & 5 & 0.12 & 0.38 & 180.00 \\
\hline 14 & 4 & 6 & 0.10 & 0.45 & 250.00 \\
\hline 15 & 5 & 6 & 0.10 & 0.40 & 190.00 \\
\hline
\end{tabular}

TABLE V

CONSIDERED CONTINGENCIES FOR UNDER STUDY TRANSMISSION SYSTEM

\begin{tabular}{|c|c|c|}
\hline Cont. No. & Monitored Tran. Line & Contingencey \\
\hline 1 & 5 & 4 \\
\hline 2 & 6 & 4 \\
\hline 3 & 7 & 4 \\
\hline 4 & 3 & 10 \\
\hline
\end{tabular}

TABLE VI

IMPORTANCE DEGREE OF TRANSMISSION PLANNING STAKEHOLDERS

\begin{tabular}{|c|c|c|}
\hline Bus No. & Type & Importance Degree (p.u.) \\
\hline 1 & G & 0.105 \\
\hline 2 & IPP1 & 0.350 \\
\hline 5 & IPP2 & 0.245 \\
\hline 3 & Disco1 & 0.1 \\
\hline 4 & Disco2 & 0.1 \\
\hline 6 & Disco3 & 0.1 \\
\hline \multicolumn{2}{|l}{ Digitised Band } & {$[0,1]$} \\
\hline
\end{tabular}

TABLE VII OPTION/STAKEHOLDER PREFERNCE

\begin{tabular}{|c|c|c|c|c|c|c|}
\hline $\begin{array}{c}\text { OPT } \\
\text { NO }\end{array}$ & G & IPP1 & IPP2 & Disco1 & Disco2 & Disco3 \\
\hline 1 & M & M & M & L & L & L \\
\hline 2 & VH & VL & VL & VH & VL & VL \\
\hline 3 & VH & VL & VL & VL & VH & VL \\
\hline 4 & M & M & M & L & L & L \\
\hline
\end{tabular}




\begin{tabular}{|c|c|c|c|c|c|c|}
\hline 5 & VH & VL & VL & VL & VL & VH \\
\hline 6 & VL & VH & VL & VH & VL & VL \\
\hline 7 & VL & VH & VL & VL & VH & VL \\
\hline 8 & M & M & M & L & L & L \\
\hline 9 & VL & VH & VL & VL & VL & VH \\
\hline 10 & L & L & L & M & M & M \\
\hline 11 & VL & VL & VH & VH & VL & VL \\
\hline 12 & L & L & L & M & M & M \\
\hline 13 & VL & VL & VH & VL & VH & VL \\
\hline 14 & L & L & L & M & M & M \\
\hline 15 & VL & VL & VH & VL & VL & VH \\
\hline
\end{tabular}

Fig. 5, shows the price profile of the transmission system under study, which is obtained by the electricity market simulator.

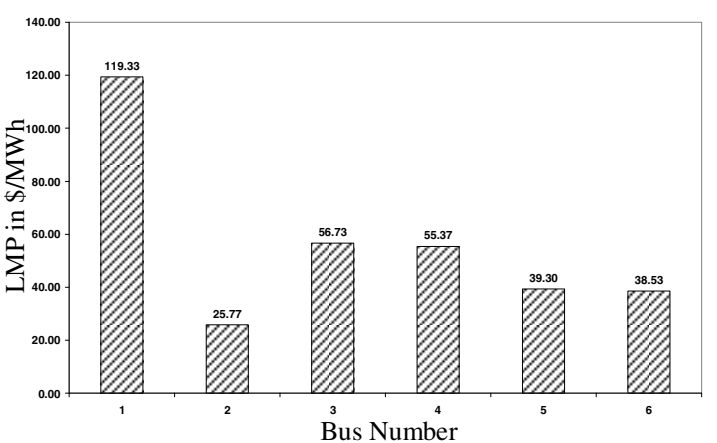

Fig. 5. Price profile of under study transmission system

As it is clear from figure 5, existing transmission system can not support the stable and full competitive electricity market as the price profile is not flat and $\mathrm{CR}_{\text {sys }}$ is $592246.3 \$ / \mathrm{h}$. In addition the system is not reliable for serving the load because of $V_{o L L}$ sys found as $81448.96 \$ / h$ for the original transmission system.

TABLE VIII

CHANGE IN POWER SYSTEM AND POWER MARKET PERFORMANCE INDICES WITH RESPECT TO VALUES FOUND FOR ORIGINAL TRANSMISSION SYSTEM NORMALIZED BASED ON THE MAXIMUM OF ABSOLUTE VALUES

\begin{tabular}{|c|c|c|c|c|}
\hline $\begin{array}{c}\text { Option } \\
\text { No. }\end{array}$ & $\begin{array}{c}\delta C R_{\text {sys }} \\
(\$ / \mathrm{h})\end{array}$ & $\begin{array}{c}\delta \text { VoL } \\
(\$ / \mathrm{h})\end{array}$ & $\begin{array}{c}\delta<\lambda> \\
(\$ / \mathrm{MWh})\end{array}$ & $\mathrm{MW}_{\mathrm{i}}$ \\
\hline 1 & -0.4965 & 0.1697 & -0.2388 & 0.1170 \\
\hline 2 & -0.4965 & 0.0870 & -0.2388 & 0.4024 \\
\hline 3 & -0.4965 & 0.1697 & -0.2388 & 0.5079 \\
\hline 4 & -0.4965 & 0.1697 & -0.2388 & 0.1451 \\
\hline 5 & 0.5035 & -0.6272 & 0.0719 & 1.0000 \\
\hline 6 & -0.4965 & 0.0870 & -0.2388 & 0.4800 \\
\hline 7 & -0.4965 & 0.0870 & -0.2388 & 0.5529 \\
\hline 8 & -0.4965 & 0.1697 & -0.2388 & 0.1018 \\
\hline 9 & -0.4965 & 0.1697 & -0.2388 & 0.4449 \\
\hline 10 & -0.4965 & -0.2895 & -0.2388 & 0.1369 \\
\hline 11 & -0.4965 & 0.0870 & -0.2388 & 0.1486 \\
\hline 12 & -0.4965 & 0.1697 & -0.2388 & 0.0817 \\
\hline 13 & -0.4965 & 0.1697 & -0.2388 & 0.4221 \\
\hline 14 & -0.4965 & -0.3963 & -0.2388 & 0.0081 \\
\hline 15 & -0.4965 & 0.2482 & -0.2388 & 0.5043 \\
\hline
\end{tabular}

Based on the Table 8, plan performance assessment from the view point of transmission planning criteria can be found as Table9.

TABLE IX

PLAN PERFORMANCE ASSESSMENT FROM THE VIEW POINT OF TRANSMISSION PLANNING CRITERIA

\begin{tabular}{|c|c|}
\hline Option No. & Performance index \\
\hline 1 & 0.8532 \\
\hline $\mathbf{2}$ & 1.7511 \\
\hline 3 & 1.6774 \\
\hline 4 & 1.2691 \\
\hline 5 & 2.0226 \\
\hline 6 & 1.8804 \\
\hline 7 & 1.6682 \\
\hline 8 & 0.6674 \\
\hline 9 & 1.4035 \\
\hline 10 & $\mathbf{2 . 2 3 4 0}$ \\
\hline 11 & 1.4756 \\
\hline 12 & 0.6473 \\
\hline 13 & 1.3719 \\
\hline 14 & 1.1397 \\
\hline 15 & 1.3044 \\
\hline
\end{tabular}

As Table 9 shows, plan number 10 has the highest performance index with the value of 2.2340 from the view point of transmission planning criteria. On the other hand, Table 10 presents the overall option assessment from the view point of market players active in central transmission planning procedure.

TABLE X

PLAN PERFORMANCE ASSESSMENT FROM THE VIEW POINT OF STAKEHOLDER PREFERNCE

\begin{tabular}{|c|c|}
\hline \multicolumn{2}{|c|}{ PREFERNCE } \\
\hline Option No. & Performance index \\
\hline 1 & 0.425 \\
\hline$\underline{\mathbf{2}}$ & 0.205 \\
\hline 3 & 0.205 \\
\hline 4 & 0.425 \\
\hline 5 & 0.205 \\
\hline 6 & 0.45 \\
\hline 7 & 0.45 \\
\hline 8 & 0.425 \\
\hline 9 & $\mathbf{0 . 4 7 5}$ \\
\hline 10 & 0.325 \\
\hline 11 & 0.345 \\
\hline 12 & 0.325 \\
\hline 13 & 0.345 \\
\hline 14 & 0.325 \\
\hline 15 & 0.345 \\
\hline
\end{tabular}

Based on Table 10, plan number 9 has the highest performance index with the value of 0.475 from the view point of transmission planning stake holders.

Finally, the selected plan considering transmission planning criteria as well as accommodation preference degree of market players is construction of a new transmission line between buses 2 and 3 (plan 6) as calculated through Table 11.

TABLE XI

FINAL PLAN PERFORMANCE ASSESSMENT CONSIDERING TRANSMISSION PLANNING CRITERIA AND THE VIEW POINT OF STAKEHOLDER PREFERNCE

\begin{tabular}{|c|c|}
\hline Option No. & Performance index \\
\hline 1 & 0.3626 \\
\hline 2 & 0.3590 \\
\hline 3 & 0.3439 \\
\hline 4 & 0.5394 \\
\hline 5 & 0.4146 \\
\hline 6 & $\mathbf{0 . 8 4 6 2}$ \\
\hline 7 & 0.7507 \\
\hline 8 & 0.2837 \\
\hline 9 & 0.6667 \\
\hline 10 & 0.7260 \\
\hline
\end{tabular}




\begin{tabular}{|l|l|}
\hline 11 & 0.5091 \\
\hline 12 & 0.2104 \\
\hline 13 & 0.4733 \\
\hline 14 & 0.3704 \\
\hline 15 & 0.4500 \\
\hline
\end{tabular}

By following the proposed methodology for transmission planning in the reference electricity market, the final plan for transmission system is found as $\{2-3,1-6,4-5,2-4,3-6,1-3,2-$ 6,4-6,1-2,3-5,1-4 . By adding these new transmission assets to the base case the Congestion Revenue for the designed transmission network becomes 0 and the mean of LMP found at different transmission connection points will be 41.47\$/MWh with the total load served.

\section{NUMERICAL STUDIES}

Transmission planning is a key issue in achieving the smooth operation of power system from view point of security and power market efficiency. The competitive market demands new tools for transmission expansion planning, which addresses market efficiency as one of the important factors in siting new transmission assets. This paper proposes a new algorithm for transmission planning, which addresses (1) minimization of investment cost (2) improving power system reliability in terms of sustainable load serving (3) maximizing power market efficiency by having a context for perfect competition (4) considering security constraints by contingency analysis and (5) accommodating stakeholders' preference in each transmission expansion option by employing fuzzy concept. The results of applying the proposed approach introduced in this paper to a test case are very promising. As mathematically modelled reference electricity market used in this paper is based on operating electricity market in Australia, authors now working on applying the proposed heuristic method to Eastern Australian transmission system as a practical case study.

\section{REFERENCES}

[1] B. Luiz Augusto Barroso(PSR/Mercados de Energia, Teofilo H. Cavalcanti(CHESF- The Sao Francisco Hydro-Electric Company, Brazil), Paul Giesbertz(DTe, The Netherland), Konrad Purchala(K.U. Leuven, Belgium), "Classification of electricity market models worldwide," 2005.

[2] “Annual Planning Report 2006” published by Queensland Electricity Transmission Corporation Limited, Powerlink Queensland

[3] “Annual Planning Report 2007" published by Queensland Electricity Transmission Corporation Limited, Powerlink Queensland

[4] Majid Oloom Buygi, Gerd Balzer, Hassan Modir Shanechi, and Mohammad Shahidehpour, "Market-Based Transmission System Planning", IEEE Transactions on Power Systems, Vol.19, No.4, November 2004

[5] F.F. Wu, F.L. Zheng, F.S. Wen, "Transmission Investment and Expansion Planning in a Restructured Electricity Market", Science Direct, Energy 312006 954-966

[6] A.K. David, Fushuan Wen, "Transmission Planning and Investment under Competitive Electricity Market Environment", 2001 Power Engineering Society Summer Metting, 15-19 July, Vancouver, Canada

[7] G. Latorre, R. D. Cruz, J. M. Aleiza, and A. Villegas, "Classification of Publications and Models on Transmission Expansion Planning", IEEE Transaction on Power Systems, Vol. 18, No.2, May 2003, pp 938-946

[8] M. Ivey, A. Akhil, D. Robinson, J. Stamp, K. Stamber, and K. Chu, "Accommodating Uncertainty in the Planning and Operation of Electric Power Systems", Sandia National Laboratories, August 2000, United States of America
[9] M.R. Hesamzadeh and H. Seifi, "A Hybrid Algorithm for Transmission Expansion Planning under Uncertainty", The 20th International Power System Conference, PSC 2005, Tehran, Iran, 14-16 November 2005

[10] M.R. Hesamzadeh and H. Seifi, " Transmission expansion planning under uncertainty", The 13th Iranian Conference in Electrical Engineering (ICEE), University of Zanjan, Volume 4, Pages 489-495, Zanjan, Iran, May 10-12, 2005

[11] M. Schwan, H.J. Koglin, "Reliability of power Transits", Electrical Engineering 83(2001) ,287-289, Springer

[12] J. Choi, A. Keib, and T. Tran "A Fuzzy Branch and Bound-Based Transmission System Expansion Planning for the Highest Satisfaction Level of the Decision Maker" IEEE Transactions on Power Systems, Vol. 20, No.1, February 2005, pp. 476-484

[13] M.R. Hesamzadeh, H. Seifi and N. Hosseinzadeh "A Hybrid Method for Transmission Expansion Planning under Uncertainty", Submitted to Australian Journal of Electrical and Electronic Engineering, Australia

[14] W. Lu, E. Bompard, R. Napoli, X. Jiang, "Heuristic Procedures for Transmission Planning in Competitive Electricity Markets", Electric Power System Research

[15] P. Sanchez-Martin, A. Ramos, and F. Alonso, "Probabilistic Midterm Transmission Planning in a Liberalized Market", IEEE Transaction on Power Systems, Vol. 20, No. 4, November 2005

[16] J. Wood, B.F. wollenberg, "Power Generation, Operation, and Control", second edition

[17] H. Wang, P. Rastgoufard "Power System Locational Marginal Pricing in Deregulated Market" Phd Thesis, Tulan university, November 2003

[18] Z. Xu, "Transmission Planning in Deregulated Environment ", IEE proceedings, Vol. 153(3), 2006, pp. 326-334

[19] M.R. Hesamzadeh, N. Hosseinzadeh, P. Wolfs, "A Forward Heuristic Procedure for Transmission Planning in Restructured Electricity Market "International Conference on Power Systems, ICPS2007, Central Power Research Institute, Bangalore, India

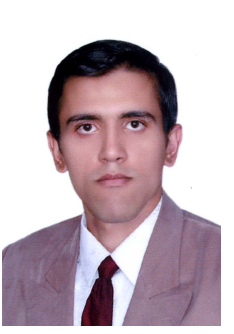

Mohammad R. Hesamzadeh received a Bachelor of Electrical Engineering in 2002 and a Master of Engineering in power systems in 2004. Currently, he is with Central Queensland University as a Senior Researcher while pursuing his Ph.D. studies. His special fields of interest include mathematical and statistical modeling and analyzing of power systems, and intelligent system applications in engineering. He is a student member of IEEE and a Professional Engineer in Australia.

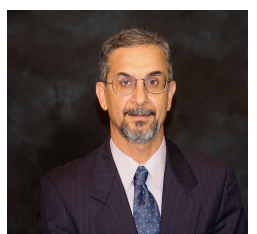

Nasser Hosseinzadeh (M'86) was born in Iran in 1960. He graduated from Shiraz University in 1986 with a Bachelor of Science degree in Electrical and Electronics Engineering. He subsequently received a Master of Science degree from Iran University of Science and Technology in 1992 and a PhD degree in Electrical Engineering from Victoria University in Australia in 1998. He worked at an Engineering Research Center in the periods of 1986-1990 and 1992-1994. He is currently the Head of Department of Systems at the Faculty of Sciences, Engineering and Health at Central Queensland University, Rockhampton, Australia. His special fields of interest include power system analysis and planning, power system stability, intelligent system applications in engineering, distributed generation and rural energy supply.

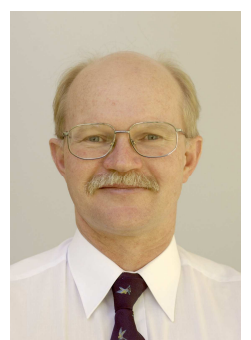

Peter Wolfs (M'80, SM'99) was born in Rockhampton Australia in 1959. He graduated from the Capricornia Institute of Advanced Education in 1980 with a Bachelor of Engineering Degree. He subsequently secured a Master of Engineering degree with the Philips International Institute in the Netherlands in 1981 and a PhD degree at the University of Queensland in 1992.

$\mathrm{He}$ is the Associate Dean (Research and Innovation) at the Faculty of Sciences, Engineering and Health at Central Queensland University. His special fields of interest include rural and renewable energy supply, electric, solar and hybrid electric vehicles and intelligent systems applications. Professor Wolfs is Senior Member of IEEE, a Fellow of Engineers Australia, a Registered 
Professional Engineer in the State of Queensland and a member of the Railway Technical Society of Australia. He is the author of more than 120 technical journal and conference publications in electrical engineering. 